\title{
T(-786)C Polymorphism of NOS3 Gene in the Yakut Population
}

\author{
Julia Solovieva $^{1}$ and Natalia Borisova ${ }^{1, *}$ \\ ${ }^{I}$ M.K. Ammosov North-Eastern Federal University, Yakutsk, Russia \\ "Corresponding author. Email: nn.borisova@s-vfu.ru
}

\begin{abstract}
Endothelial NOS (nitric oxide synthase 3) is an enzyme that synthesizes nitric oxide, which in turn plays a crucial role in regulating vascular tone, cell proliferation, leukocyte adhesion, and platelet aggregation. This enzyme in humans is encoded by NOS3 gene. The aim of our research was to study T (-786) C polymorphism of NOS3 gene in healthy individuals of the Yakut population. The experimental part of the research was carried out in "Molecular Medicine and Human Genetics" of the NEFU Medical Institute. In total, 270 DNA samples of healthy Yakuts were examined (71 men: women 199, average age $49.18 \pm 14.36$ years). The single nucleotide polymorphism was determined by realtime PCR with fusion of fluorescent labeled hybridization products followed by analysis of melting curves. As a result of genotyping T (-786) C polymorphism of NOS3 gene, the predominance of T allele $(95.37 \%)$ was established among the Yakut population. Among all examined patients, carriers of the homozygous TT genotype were dominated -246 people $(91.11 \%)$. The heterozygous TC genotype was $8.52 \%$ (23), whereas the homozygous C allele genotype occurred only in $0.37 \%$ of cases (1). When compared with populations of the world, according to the "1000 genomes," C allele among the Yakuts was less common than among the population of North America, South America, Europe, India, Oceania, Africa and Asia. Thus, the Yakut population is characterized by a unique distribution of genotypes of T (-786) C polymorphism of NOS3 gene among populations of the world.
\end{abstract}

Keywords: T(-786)C Polymorphism, Endothelial NOS, NOS3 gene, Yakut population

\section{INTRODUCTION}

With the development of personalized medicine, single nucleotide polymorphisms of genes take an increasing role in the diagnosis and individual selection of drug therapy. It is known that there are statistically significant differences between ethnic groups in the frequency of occurrence of polymorphic gene variants. Therefore, it has a perspective for studying the NOS3 gene and its polymorphic variants in the Yakut population. Endothelial NOS (eNOS), also known as nitric oxide synthase 3 (NOS3), is an enzyme that is encoded in humans by the NOS3 gene located in the $7 \mathrm{q} 35-7 \mathrm{q} 36$ region of chromosome 7 [1]. This enzyme is one of three isoforms that synthesize nitric oxide (NO), a small gaseous and lipophilic molecule that participates in several biological processes. NO produced by the NOS3 gene in vascular endothelium plays a crucial role in regulating vascular tone, cell proliferation, leukocyte adhesion, and platelet aggregation [2].

Some single nucleotide polymorphisms NOS3 affect the expression or activity of the NOS3 enzyme, thereby affecting the NO formation. Disruption of NO production is involved in the pathogenesis of several diseases such as hypertension, preeclampsia, diabetes mellitus, obesity, erectile dysfunction and migraine. A large number of studies have shown that polymorphisms in the NOS3 gene affect the predisposition to these diseases [3].

At the moment, polymorphisms of 11 loci have been studied, 8 polymorphisms of NOS3 associated with cardiovascular diseases have been described, one of which was a single nucleotide polymorphism - $\mathrm{T}(-786)$ C [4]. This polymorphism leads to a decrease in the expression of the NOS3 enzyme and, accordingly, to a decrease in the NO production. Most researchers agree 
that this polymorphism predisposes to arterial hypertension [5, 6], as well as coronary heart disease patients with the $\mathrm{CC}$ genotype are characterized by a significantly increased risk of the early episode of coronary heart disease [7-9] and, moreover, the development of myocardial infarction [10] or paroxysm of atrial fibrillation [11].

Polymorphism is also associated with many diseases mediated by endothelial dysfunction [12]: allergic diseases [13], preeclampsia [14, 15], psyoriasis [16], as well as erectile dysfunction [17]. Ben Nasr and coauthors (2017) established the association of $\mathrm{T}$ (-786) C polymorphism with the risk of chronic obstructive pulmonary disease. They found that this polymorphism correlated with enhanced airflow restriction, which might be associated with altered nitric oxide levels and increased lipid peroxide content in patients with CC genotype [18].

This polymorphism was associated with an increased risk of diabetic nephropathy, retinopathy and migraine in various studies [19].

Thus, the $\mathrm{T}(-786) \mathrm{C}$ polymorphism of the NOS3 gene has prospects for predicting not only cardiovascular disease, but also all conditions associated with endothelial pathology.

The aim of our study was to study the $\mathrm{T}(-786) \mathrm{C}$ polymorphism of the NOS3 gene in healthy individuals of the Yakut population.

\section{MATERIALS AND METHODS}

The experimental part of the research was carried out in the Research Laboratory "Molecular Medicine and Human Genetics" of the Medical Institute of NorthEastern Federal University. DNA samples of residents of the Vilyu group of uluses were used for the study. A total of 270 DNA samples of healthy Yakut volunteers by ethnicity were investigated (third generation Yakuts included). 71 DNA samples belonged to male individuals and 199 samples to female individuals. The average age of the study participants was $49.18 \pm 14.36$ years. The criteria for exclusion from the study were: age under 18 years old, chronic cardiovascular disease, cancer, viral hepatitis, alcohol abuse. All individuals completed a questionnaire with informed consent to conduct a genetic study.

DNA was isolated from frozen whole blood by the set "RealBest - DNA-express genetics." Single nucleotide polymorphism (SNP) was determined by real-time polymerase chain reaction with fusion of fluorescent label hybridization products followed by analysis of "RealBest-Genetics NOS T (-786) C" melting curves. The principle of the method is based on amplification of melting curves of hybrid complexes of PCR products and specific probes.
$50 \mu$ of isolated DNA solution was added to the tubes with the finished lysed PCR reaction mixture (FRM) without precipitate. Tightly covered with an optical film, the tubes were placed in a mini-shaker and the contents of the tubes were mixed at $1200 \mathrm{rpm}$ for 1 minutes.

Aplication and detection of melting curves were carried out according to the protocol in Table 1.

Table 1. Protocol of amplification reaction and detection of melting curves

\begin{tabular}{|l|l|}
\hline Stage & Conditions \\
\hline stage 1 & $50^{\circ} \mathrm{C}-2$ minutes \\
\hline Step 2: & $95^{\circ} \mathrm{C}-2$ minutes \\
\hline Stage 3 & 50 cycles: \\
& $94{ }^{\circ} \mathrm{C}-10 \mathrm{sec}$ \\
& $60^{\circ} \mathrm{C}-20 \mathrm{sec}$ \\
\hline Step 4: & "melting curve" from $27^{\circ} \mathrm{C}$ with a pitch of \\
& $1^{\circ} \mathrm{C}$ for 5 seconds (fluorescence \\
& measurement at each step) \\
\hline Step 5: & $10^{\circ} \mathrm{C}-1$ minute \\
\hline
\end{tabular}

Channel for detecting duplex melting curves of a specific DNA probe and amplification product for recording genetic polymorphism is: "FAM."

Conditions of analysis and results: the presence of one melting peak was recorded, for the control sample "Normal homozygote" (KO1) in the detection channel "FAM", the same for the control sample "Mutant homozygote" (KO2).

For the TT homozygote, the presence of one melting peak at a melting point value not exceeding $2{ }^{\circ} \mathrm{C}$ from the melting point for KO1 was considered (Fig. 1).

The presence of one melting peak at a melting point value other than not more than $2^{\circ} \mathrm{C}$ from the melting point for $\mathrm{KO} 2$ was considered for the $\mathrm{CC}$ homozygote and the presence of two melting peaks, wherein the temperature of one differs by no more than $2^{\circ} \mathrm{C}$ from the melting point for $\mathrm{KO} 1$, for heterozygote $\mathrm{TC}$ and the temperature of the second differs by not more than $2^{\circ} \mathrm{C}$ from the melting point for $\mathrm{KO} 2$ (Fig. 2).

The data processing was carried out by the statistical programs "Office Microsoft Excel 2010" and "IBM SPSS Statistics 23." The frequency of alleles and genotypes of the $\mathrm{T}(-786) \mathrm{C}$ polymorphism of the NOS3 gene was tested for compliance with Hardy-Weinberg equilibrium. The frequency of alleles and genotypes between the male and female groups were compared with a Yates-adjusted continuity test. The results were considered significant, with $\mathrm{p}$ less than $0.05(\mathrm{p}<0.05)$. 


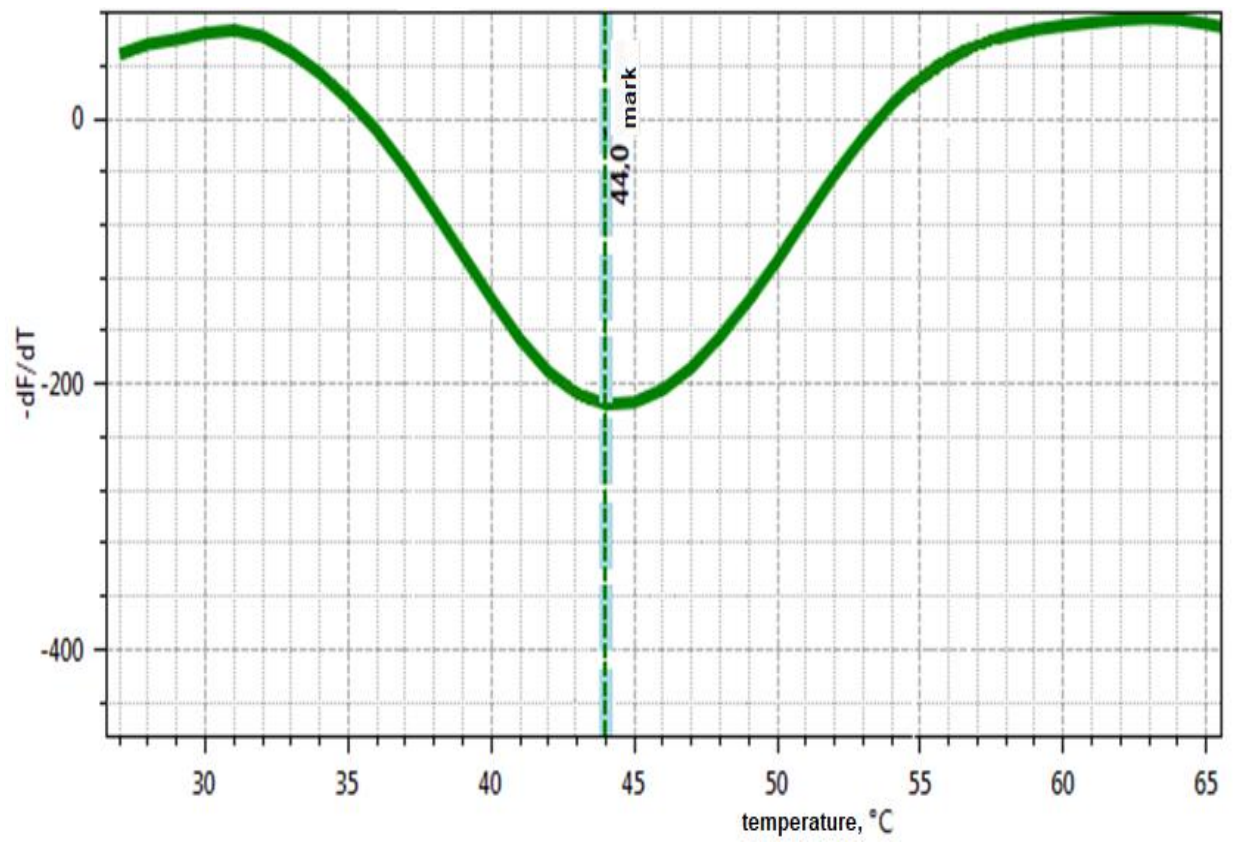

Figure 1. The melting curve of the TT homozygote of the T (-786) $\mathrm{C}$ polymorphism of the NOS3 gene $\left(\mathrm{T}\right.$ allele $\left.-44^{\circ} \mathrm{C}\right)$.

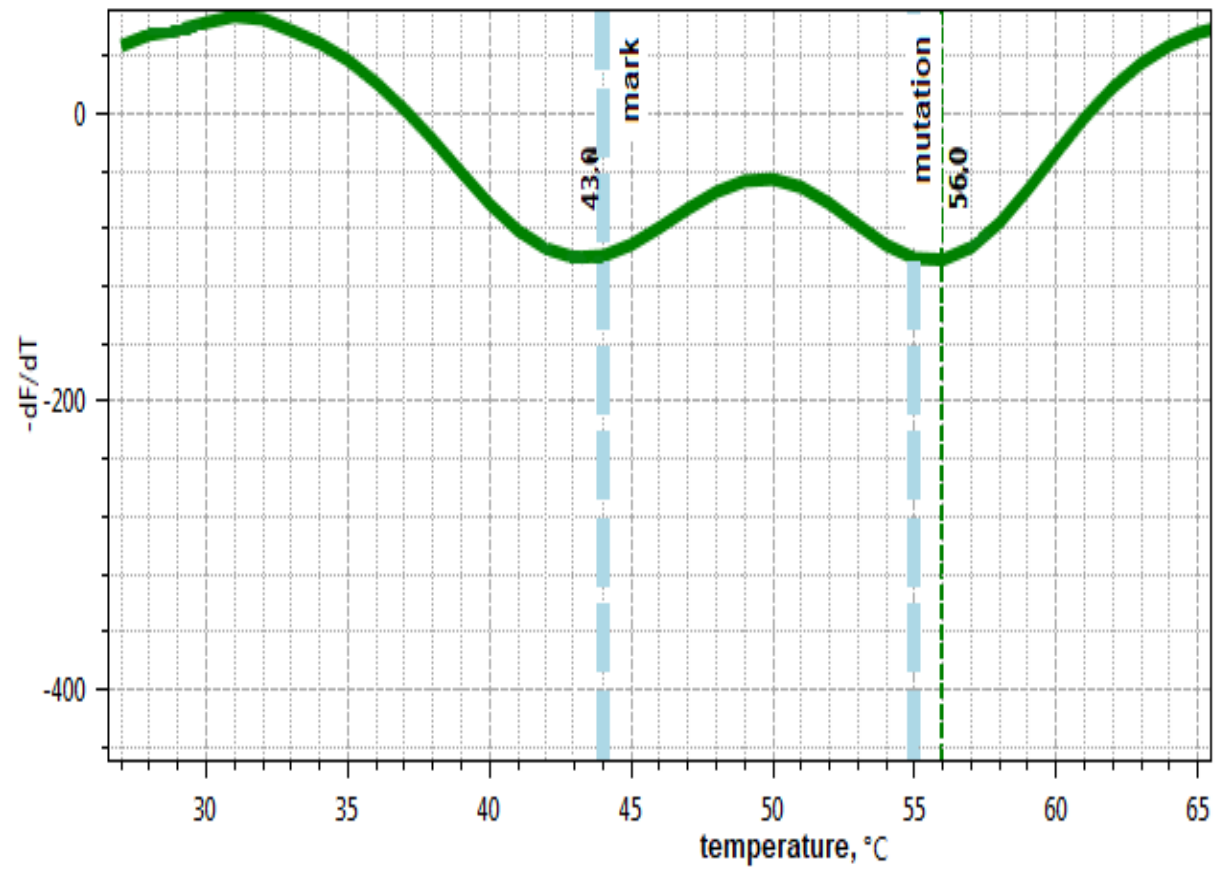

Figure 2. The melting curve of the TC heterozygote of the $\mathrm{T}(-786) \mathrm{C}$ polymorphism of the NOS 3 gene $\left(\mathrm{T}\right.$ allele $-43{ }^{\circ} \mathrm{C}$, $\mathrm{C}$ allele $-56^{\circ} \mathrm{C}$ ).

\section{RESULTS AND DISCUSSION}

The predominance of the $\mathrm{T}$ allele $(95.37 \%)$ was established among the Yakut population as a result of the genotyping of the polymorphic variant $\mathrm{T}(-786) \mathrm{C}$ of the NOS3 gene, which corresponds to the previously published results of K.V. Komzin and co-authors (2018) [20], according to which the Yakut population was also characterized by the predominance of the $\mathrm{T}$ allele $94.3 \%(1 / 42(1, n)$
The frequency analysis of occurrence of genotypes of the polymorphic variant T (-786) C of the NOS3 gene revealed that carriers of the homozygous genotype TT 246 people $(91.11 \%)$ predominated among all examined individuals.

The heterozygous TC genotype was $8.52 \%$ (detected in 23 individuals), whereas the homozygous genotype of allele $\mathrm{C}$ occurred only in $0.37 \%$ of cases (in one individual), which is also consistent with previous studies [20]. 
Analysis of the genotype distribution revealed no significant differences between observed and expected distributions $(1 / 42=0,337, \mathrm{p}=0,561)($ Table 2$)$.

Table 2. Frequency of occurrence of $\mathrm{T}(-786) \mathrm{C}$ polymorphism genotypes and alleles NOS3 gene among the Yakut population

\begin{tabular}{|l|l|l|}
\hline$n=270$ & $\begin{array}{l}\text { Observed } \\
\text { distribution }\end{array}$ & $\begin{array}{l}\text { Expected } \\
\text { distribution }\end{array}$ \\
\hline $\begin{array}{l}\text { Genotype, } n(\%) \\
\text { TT }\end{array}$ & $246(91.11)$ & $245,58(90,96)$ \\
TC & $23(8.52)$ & $23,84(8,83)$ \\
CC & $1(0.37)$ & $0,58(0,21)$ \\
\hline Allele, $n(\%)$ & & \\
T & $515(95.54)$ & \\
C & $25(4.46)$ & \\
\hline$X 2$ & 0.337 & \\
\hline$p$ & 0.5614 & \\
\hline
\end{tabular}

According to open sources of the 1000 Genomes project [21], a high frequency of the mutant $\mathrm{C}$ allele was observed in the European population $-44 \%$, less often in the American population - $26 \%$, in the populations of South Asia - $25 \%$, Africa - $14 \%$. The least common mutant allele was found in East Asian populations $12 \%$ (Fig. 3).
When compared with world populations, according to "1000 genomes," the $\mathrm{T}$ allele among Yakuts is less common than among the population of North America, South America, Europe, India, Oceania and Africa. However, in order to determine the prospect of studying this polymorphism, we compared the distribution of genotypes among Asian populations of the world (Table 3).

Table 3. Distribution of genotypes T (-786) C polymorphism of NOS3 gene in Asian populations of the world (according to "1000 genomes" [21]

\begin{tabular}{|l|l|l|l|l|l|}
\hline \multirow{2}{*}{ Population } & \multicolumn{3}{|l|}{ Genotype } & \multirow{2}{*}{$X^{2}$} & \multirow{2}{*}{$p$} \\
\cline { 2 - 5 } & TT & TC & CC & & \\
\hline Yakuts $\mathrm{n}=270$ & 246 & 23 & 1 & & \\
\hline The Dai $\mathrm{n}=93$ & 71 & 21 & 1 & 13.636 & 0.001 \\
\hline Chinese $\mathrm{n}=105$ & 75 & 28 & 2 & 23.954 & $<0.00001$ \\
\hline Japanese $\mathrm{n}=104$ & 83 & 21 & 0 & 10.228 & 0.006 \\
\hline Koreans $\mathrm{n}=99$ & 78 & 19 & 2 & 10.928 & 0.004 \\
\hline Bengalese $\mathrm{n}=86$ & 43 & 37 & 6 & 74.132 & $<0.00001$ \\
\hline Indians $\mathrm{n}=102$ & 55 & 40 & 7 & 68.357 & $<0.00001$ \\
\hline Pakistanis $\mathrm{n}=96$ & 52 & 39 & 5 & 65.078 & $<0.00001$ \\
\hline
\end{tabular}

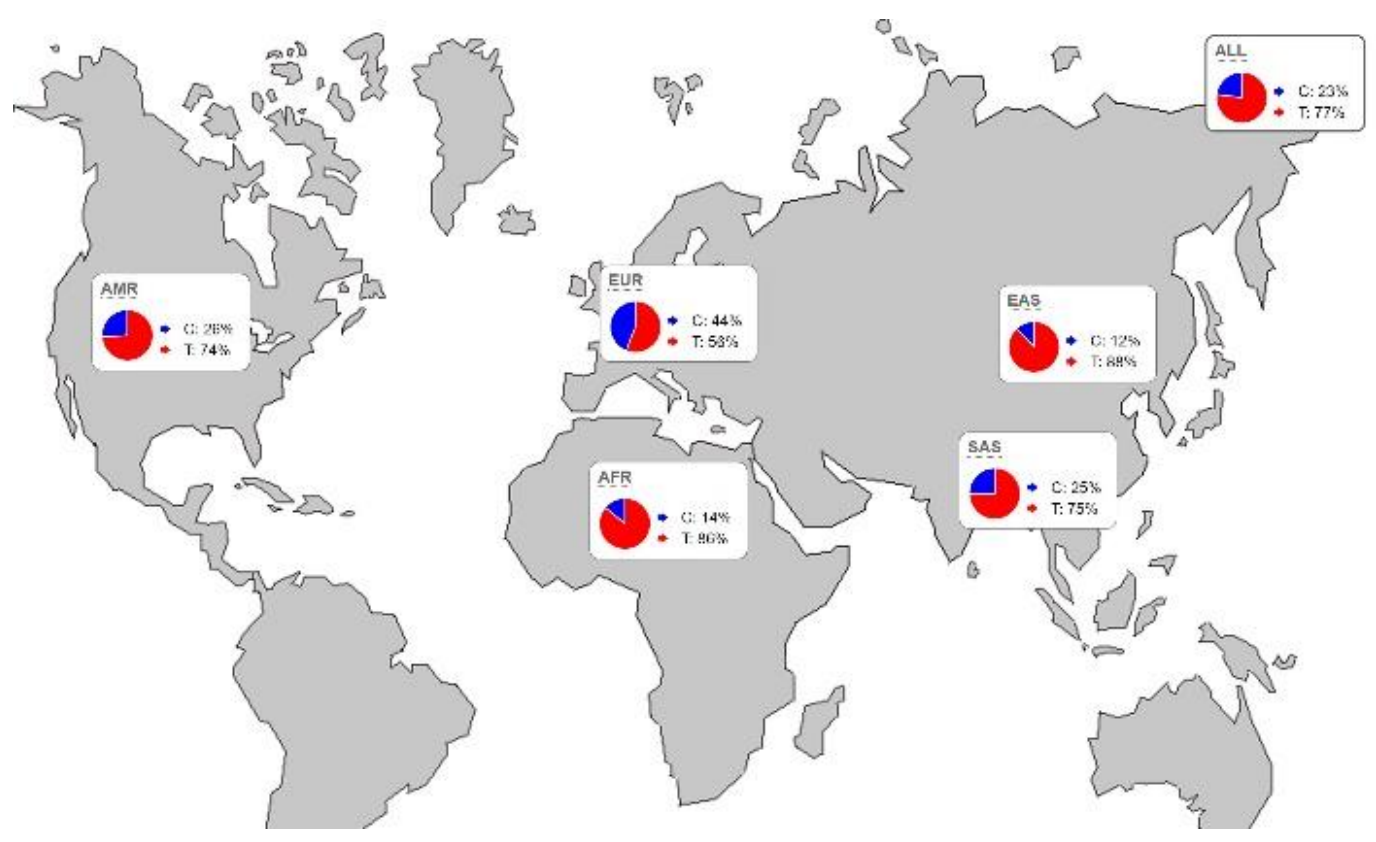

Figure 3. Frequency of occurrence of alleles of T (-786) C polymorphism of NOS3 gene according to "1000 genomes" [21]

The distribution of genotypes among Asian populations in the world revealed that the Yakut population had significant differences with all populations included in the study.
So, the mutant allele $\mathrm{C}$ among the studied populations was the least common in the Yakut population $-4.63 \%$, in Japanese $-10.1 \%$, in Korean $11.62 \%$, as well as in dai $-12.37 \%$. The largest 
difference $(\mathrm{p}<0.00001)$ with the Yakut population was shown by the Chinese $-15.24 \%$, Bengalese $-28.48 \%$, Indians $-26.47 \%$ and Pakistanis $-25.52 \%$.

Thus, the Yakut population is characterized by a unique distribution of genotypes of the $\mathrm{T}(-786) \mathrm{C}$ polymorphism of the NOS3 gene among Asian populations, thereby prospecting for studying this polymorphic variant in the development of cardiovascular pathology: arterial hypertension, coronary heart disease, including the development of myocardial infarction, ischemic stroke, as well as many pathological conditions associated with endothelial dysfunction: allergic diseases, gestosis and preeclampsia, psyoriasis, erectile dysfunction, fibrous changes in lung and liver tissue, etc.

\section{CONCLUSION}

According to the results of the present study, the population of healthy Yakuts living on the territory of the Vilyu group of uluses of the Republic of Sakha (Yakutia) is characterized by a significant predominance of carriers of the $\mathrm{T}$ allele $(95.54 \%)$ and the TT genotype $(91.11 \%)$ of the polymorphic variant $\mathrm{T}(-786)$ $\mathrm{C}$ of the NOS3 gene.

\section{ACKNOWLEDGMENTS}

The study was carried out with the support of the Innovation Assistance Fund (Contract No. 13755SU/2018 dated 02.04.2019 (code 0045258), application No. 53541, competition UMNIK-18 (a), Republic of Sakha (Yakutia) - 2018).

\section{REFERENCES}

[1] J.E. Fish, P.A. Marsden, Cellular and Molec. Life Sci. 63(2) (2006) 144-162.

[2] U. Förstermann, W.C. Sessa, Europ. Heart J. 33(7) (2012) 829-837.

[3] G.H. Oliveira-Paula, R. Lacchini, J.E. TanusSantos, Gene 575(2Pt3) (2016) 584-599.

[4] W. Niu, Y. Qi, PLoS One, 6 (2011) e24266.

[5] Z. Farbood et al., Biochem. Genet. 58(4) (2020) 518-532.

[6] M.E. Hyndman, H.G. Parsons, S. Verma et al., Hypertens. 39(4) (2002) 919-922.

[7] R. Alvarez, P. González, A. Batalla et al., Nitric Oxide 5(4) (2001) 343-348.

[8] S.A. Afanasiev, E.F. Muslimova, T.Y. Rebrov et al., Kardiol., Sep. 56(9) (2016) 5-10.

[9] C.R. Lee, K.E. North, M.S. Bray et al., Pharmacog. Genomics 16(12) (2006) 891-899.
[10] M. Nakayama, H. Yasue, M. Yoshimura et al., Am. J. Cardiol. 86(6) (2000) 628-634.

[11] B. Giusti, A.M. Gori, R. Marcucci et al., PLoS One 2(6) (2007) e495.

[12] Y. Luo, Y. Wang, W. Luo, J. Cell. Biochem. 121(1) (2020) 363-370.

[13] L.I. Holla, A. Stejskalova, V. Znojil, A. Vasku, 141(2) (2006) 103-109.

[14] P.K. Aggarwal, V. Jain, V. Jha, Hypertens. Res. 33(5) (2010) 473-477.

[15] B. Dai, T. Liu, B. Zhang et al., Gene 519(1) (2013) 187-193.

[16] P. Coto-Segura, E. Coto, A. Mas-Vidal et al., Arch. Dermatol. Res. 303(6) (2011) 445-449.

[17] D. Ors, A. Segura, V. Arrarte et al., Rev. Int. Androl. 1 (2020) S1698-031X(20)30022-4.

[18] H. Ben Nasr, S. Bchir, A. Ben Anes et al., Cytokine 93 (2017) 66-73.

[19] V.V. Zinchuk, D.D. Zhadko, J. of the State Med. Univ. 3 (2017) 267-274.

[20] K.V. Komzin, P.G. Petrova, A.A. Strekalovskaya et al., Wiad Lek 71(9) (2018) 1742-1748.

[21] 1000 Genomes Site. Retrieved from: http://www.internationalgenome.org/ 